\title{
Strategi Pemasaran Pantai Dream Island Di Mertasari Desa Intaran Sanur Kauh Kota Denpasar
}

Laura Therecia Samosira, 1, I Gusti Agung Oka Mahaganggaa, 2

1laurathereciasamosir@gmail.com, 2okamahagangga@unud.ac.id

a Program Studi Sarjana Destinasi Pariwisata, Fakultas Pariwisata, Universitas Udayana, Jl. Dr. R. Goris, Denpasar, Bali 80232 Indonesia

\begin{abstract}
Tourism in Indonesia has recently grown rapidly in one of them in the city of Bali. Bali has a very beautiful natural potential, one of the natural potentials developed is coastal tourism. Dream Island Mertasari Sanur Beach is one of the beaches that is still new but has a lot of potentials. Therefore, this study was conducted to determine the existing conditions and marketing strategies that exist on Dream Island the Mertasari Beach Sanur Kauh City of Denpasar.

The method used in this study is a qualitative descriptive method with data sources in the form of primary data and secondary data. The primary data in this study are data sourced from direct observation to the location of the study and by interviewing informants. While secondary data in this study are data obtained from documentation and literature to complete the primary data. The technique of determining the informants used was purposive sampling.

The results showed that the existing conditions on Dream Island Beach based on Concept $4 a$ were still lacking. The condition of the attraction is very good but for access and facilities still, have some disadvantages that need to be improved in the future. The reality that is on Dream Island Beach only consists of private parties and village institutions. The marketing strategy at Dream Island Beach has not been optimal due to several problems such as business license constraints and lack of cooperation with promotional media.
\end{abstract}

Keywords: Marketing Strategic, attraction, Dream Island Beach

\section{PENDAHULUAN}

Pariwisata Indonesia belakangan ini sedang mengalami tahap pengembangan yang cukup signifikan. Pengembangan pariwisata dilakukan agar terjadi pemerataan pendapatan daerah. Sesuai dengan UU No 10 Tahun 2009 yang menyebutkan bahwa dengan adanya daya tarik wisata pada suatu daerah akan memberikan keuntungan antara lain: meningkatkan pendapatan asli daerah, meningkatkan taraf hidup masyarakat lokal, dan memberikan lapangan kerja bagi pengangguran, serta dapat ikut serta dalam melestarikan alam dan budaya.

Indonesia memiliki potensi alam yang indah dan beragam. Terdiri dari banyak pulau yaitu sekitar 17.000 pulau yang ada di Indonesia. Oleh karena itu banyak tempat wisata yang dikembangkan di pulau - pulau Indonesia salah satu pulau yang sangat berkembang adalah Pulau Bali.

Pulau Bali merupakan pulau yang sudah terkenal ke seluruh dunia. Banyak wisatawan yang melakukan perjalanan wisata ke Bali. Pulau yang dijuluki sebagai pulau dewata ini menyimpan banyak keindahan alam seperti pantai, gunung, danau, dan atraksi budaya yang sudah terkenal sejak seratus tahun lalu (Anom, dkk, 2017).

Masyarakat lokal Bali sudah sangat dekat dengan kegiatan pariwisata. Pekerjaan di sektor pariwisata seperti guide, menyediakan homestay, bekerja di tour and travel, dan jasa pariwisata lainnya sudah menjadi hal umum di Bali. Pariwisata berperan penting dalam meningkatkan taraf hidup dan sebagai sumber mata pencaharian (Elsha, 2017)

Daya tarik wisata yang ada di Bali ada beragam. Salah satu yang paling diminati wisatawan adalah keindahan pantai. Ada berbagai macam kawasan pantai di Bali yaitu seperti di daerah Kuta, Jimbaran, Seminyak, Legian, dan Sanur. Pantai di Bali terkenal dengan keindahan panorama alamnya (sunset maupun sunrise). Salah satu pantai yang terkenal di Bali adalah pantai Sanur. Pantai Sanur dikenal di dunia internasional oleh seorang pelukis yang berasal dari Belgia bernama A. J. Le Mayeur yang datang ke Bali pada tahun 1932.

Kawasan Sanur terdiri dari beberapa pantai yang berdekatan seperti, pantai Matahari Terbit, Pantai Segara Ayu, Pantai Bali Beach, Pantai Semawang, Pantai Shindu, dan Pantai Karan. Namun terdapat sebuah pantai yang 
memiliki keunikan tersendiri yaitu Dream Island yang merupakan bagian Pantai Mertasari.

Pantai Dream Island berdiri sejak tahun 2016. Pada awalnya sejak bulan Februari sudah dibuka namun sempat tutup karena kendala sampah. Setelah beberapa bulan masalah sampah ini dapat ditangani dan akhirnya pantai ini mulai beroperasi lagi sejak 19 September 2016 sampai sekarang. Pantai ini memiliki keunikan yaitu wisatawan dapat menikmati keindahan sunrise dan sunset sekaligus.

Pantai ini masih terbilang baru sebagai daya tarik wisata sehingga masih banyak wisatawan yang belum mengetahui keberadaanya. Pantai ini masih dalam proses pengembangan namun sudah memiliki potensi pariwisata yang baik. Terdapat atraksi seperti memberi makan hiu, menunggangi kuda dan unta, juga menikmati spa dipinggir pantai.

Objek wisata pantai ini dimiliki oleh perorangan dan bekerjasama dengan pihak swasta yang memberikan investasi dana untuk mengelola kawasan wisata ini. Pihak manajemen pemasaran Pantai Dream Island belum maksimal dalam memasarkan produk wisata yang ada. Oleh karena itu dibutuhkan rancangan pemasaran yang mudah dipahami serta komunikatif agar wisatawan tertarik untuk mengunjungi pantai ini. Sampai saat ini wisatawan lokal masih mendominasi kunjungan wisatawan di pantai ini, namun seiring dengan perkembangan waktu pantai ini sudah mulai didatangi oleh wisatawan asing yaitu wisatawan yang berasal dari Cina.

Tabel 1. Jumlah kunjungan wisatawan di Pantai Dream Island tahun 2017

\begin{tabular}{|l|c|r|}
\hline Bulan & $\begin{array}{c}\text { Jumlah } \\
\text { Kunjungan } \\
\text { wisatawan }\end{array}$ & Pertumbuhan \\
\hline Januari & 6781 & $0 \%$ \\
\hline Februari & 4722 & $-44 \%$ \\
\hline Maret & 3586 & $-32 \%$ \\
\hline April & 6476 & $45 \%$ \\
\hline Mei & 8631 & $25 \%$ \\
\hline Juni & 10846 & $20 \%$ \\
\hline
\end{tabular}

\begin{tabular}{|l|l|r|}
\hline Juli & 8310 & $-31 \%$ \\
\hline Agustus & 6598 & $-26 \%$ \\
\hline September & 6450 & $-2 \%$ \\
\hline Oktober & 4443 & $-45 \%$ \\
\hline November & 6673 & $33 \%$ \\
\hline Desember & 7431 & $10 \%$ \\
\hline
\end{tabular}

Sumber: Hasil penelitian, 2018

Melalui Tabel 1 dapat dilihat pertumbuhan wisatawan yang ada di Pantai Dream Island fluktuatif. Untuk kunjungan wisatawan yang tertinggi terjadi di bulan Juni dengan jumlah kunjungan 10846 dengan tingkat pertumbuhan $20 \%$ yang terdiri dari orang dewasa dengan anak-anak. Dan kunjungan terendah terjadi di bulan Maret yaitu sebesar 3586 dengan persentase $-32 \%$. Pantai yang masih terbilang baru ini masih sangat perlu untuk dikembangkan. Dengan potensi yang dimiliki pantai ini diharapkan dapat mendatangkan wisatawan yang lebih banyak lagi. Sehingga dengan adanya potensi wisata yang dimiliki oleh Pantai Dream Island dibutuhkan perencanaan strategi pemasaran wisata yang berbasis kondisi eksisting.

\section{TINJAUAN PUSTAKA}

\subsection{Telaah Hasil Penelitian Sebelumnya.}

Berdasarkan penelitian sebelumnya dalam jurnal ilmiah oleh Ratu Cristina dkk, (2016) pada Jurnal Destinasi Pariwisata Vol. 4 No.1 yang berjudul " Stategi Pemasaran Desa Wisata Blimbingsari Kabupaten Jembrana" bahwa penelitian ini membahas tentang strategi pemasaran yang ada di desa blimbingsari. Penelitian selanjutnya yakni dilakukan oleh Joehastanti Jenny (2012) pada jurnal Ilmu Manejemen, REVITALISASI Vol.1 No.2 yang berjudul " Strategi Pemasaran Wisata Alam Untuk Meningkatkan Kunjungan Wisata Di Kawasan Wisata Kabupaten Kediri" penelitian ini membahas tentang strategi pemasaran yang dilakukan dengan menganalisis faktor eksternal dan internal yang mempengaruhi kunjungan wisatawan ke Kabupaten Kediri. Penelitian selanjutnya yang dilakukan oleh Kartha N dkk, (2014) pada jurnal Manajemen, Strategi Bisnis, dan Kewirausahaan Vol. 8 No.1 yang berjudul “ 
Strategi Komunikasi Pemasaran Ekowisata Pada Destinasi Wisata Dolphin Hunting Lovina". Penelitian ini membahas tentang strategi komunikasi pemasaran dengan design metodologi yang dilakukan adalah pendekatan marketing komunikasi.

\subsection{Landasan Konsep}

Untuk menganalisis permasalahan yang terdapat dalam penelitian ini, digunakan beberapa konsep yaitu Konsep Wisata Pantai (Yulianda,2007) Konsep 4A (Cooper dkk, 1996) Konsep Strategi (David,2011), Konsep Pemasaran (Kotler dkk, 2012) Konsep Strategi Pemasaran (Tjiptono,2006) Konsep Strategi Bauran Pemasaran (Kotler \& Armstrong, 1997).

\section{METODE PENELITIAN}

Penelitian ini menggunakan metode kualitatif. Jenis data yang digunakan dalam penelitian ini yakni data kualitatif (Moleong, 2012) dan data kuantitatif (Kusmayadi, 2000). Sumber data yakni data primer dan sekunder (Moleong,2005). Data yang diperoleh dalam penelitian ini melalui teknik pengumpulan data observasi (Sugiyono 2014), wawancara (Setyadin, 2005), dan studi dokumentasi (Creswell, 2012). Teknik penentuan informan menggunakan yakni metode Purposive sampling (Bungin, 2007).

\section{HASIL DAN PEMBAHASAN}

\subsection{Gambaran Umum}

Pantai Dream Island adalah salah satu destinasi yang masih baru dikembangkan. Pantai ini baru berdiri sejak 19 September 2016 namun pantai ini memiliki potensi pariwisata yang sangat indah sehingga apabila dapat dikembangkan dengan baik pantai akan menjadi salah satu destinasi yang dapat menarik perhatian wisatawan. Untuk dapat sampai ke pantai Dream Island memakan waktu sekitar 27 menit dari Bandar udara I Gusti Ngurah Rai yang berjarak kira-kira 15,4km. Dan dari pusat kota Denpasar memakan waktu 24 menit yang berjarak kira-kira 11,6km. Adapun batas-batas Desa Pekraman Intaran yakni sebagai berikut :

1. Sebelah Utara: Desa Pakraman Sanur

2. Sebelah Timur: Pantai, Selat Badung

3. Sebelah Selatan: Pantai, Selat Badung
4. Sebelah Barat: Desa Pekraman Renon, Desa Pekraman Penyaringan dan Desa Pakraman Sidakarya

Desa Pekraman Intaran Dibagi ke dalam dua Desa Dinas Yakni Kelurahan Sanur dan Desa Sanur Kauh. Kelurahan Sanur dipimpin oleh seorang Lurah sedangkan Desa Sanur Kauh Dipimpin oleh seorang Kepala Desa. Kelurahan sanur memiliki wilayah seluas $402 \mathrm{Ha}$, sedangkan Desa Sanur Kauh memiliki wilayah seluas 386 Ha. Luas total dari Desa Pekraman intaran adalah $788 \mathrm{Ha}$.

\subsection{KONDISI EKSISTING}

Identifikasi kondisi eksisting merupakan hal yang harus dilakukan dalam sebuah penelitian tujuannya adalah untuk melihat kondisi dan situasi yang sedang berlangsung saat ini. Peninjauan dilakukan berdasarkan realita kondisi yang sedang terjadi dilapangan pada saat penelitian ini dilakukan. Hal ini sangat penting dilakukan ketika mengadakan sebuah penelitian agar bisa mendapatkan sebuah data yang up to date. Oleh karena itu peneliti ingin mengidentifikasi kondisi eksisting yang ada di Pantai Dream Island berdasarkan konsep 4A yaitu attraction, accessibility, amenity dan ancilliary.

\section{Attraction (Atraksi)}

Atraksi wisata alam yang dapat dinikmati di Pantai Dream Island cukup unik karena di pantai ini kita bisa menikmati sunrise dan sunset sekaligus. Hal ini dikarenakan kondisi geografis pantai Dream Island yang terletak di daerah Sanur yaitu tempat dimana wisatawan biasanya menikmati sunrise dipagi hari. Namun karena pantai ini berada di bagian barat Pantai Sanur jadi wisatawan juga dapat menikmati sunset disore hari. Ini merupakan suatu keunukan yang dimiliki oleh Pantai Dream Island sehingga banyak wisatawan yang penasaran dan tertarik untuk menyaksikannya.

Dari hasil observasi yang dilakukan, di Pantai Dream Island atraksi yang dapat di lakukan di pantai ini sangat banyak. Kegiatan wisata yang dapat kita nikmati adalah seperti wisata air yaitu: sepeda air, cano, snorkeling, berkeliling dengan kuda atau unta dan memberi makan hiu. Wisata memberi makan hiu juga menjadi salah satu daya tarik dari Pantai Dream Island. Hal ini terjadi dikarenakan pantai ini merupakan satu-satunya 
pantai yang menyediakan wisata memberikan makan hiu. Ini merupakan pengalaman yang menyenangkan bagi wisatawan karena mereka dapat langsung berenang dan berinteraksi langsung dengan ikan hiu. Jenis hiu yang ada ditempat ini adalah hiu cendana hiu ini tidak agresif sehingga aman untuk berinteraksi dengan wisatawan. Ikan hiu yang berada di tempat ini merupakan hasil tangkapan nelayan setempat, namun nelayan tersebut menawarkan ke pihak pengelola agar merawatnya. Oleh karena itu pengelola memanfaatkan momen tersebut untuk menjadikan salah satu daya tarik wisatanya. Namun ketika hiu tersebut sudah mulai besar akan dilepaskan lagi ke laut. Untuk sampai ke tempat pemeliharaan ikan hiu kita harus menyebrang menggunakan fastboat. Selain itu wisatawan juga dapat menikmati performance dari penari Bali dan juga disk jockey. Disana juga terdapat spot foto yang menarik dan tidak jaran juga banyak wisatawan yang melalukan prewedding disana.

\section{Accessibility (Aksesibilitas)}

Berdasarkan observasi peneliti Pantai Dream Island Mertasari Sanur yang terletak di Jalan Penggembak No. 44, Sanur Kauh, Denpasar Selatan, sudah memiliki akses jalan yang bagus. Pantai ini bisa ditempuh hanya selama 15 menit dari pusat Kota Denpasar. Infrastruktur jalan dari Kota Denpasar ke Pantai Dream Island sudah bagus karena seluruh jalannya sudah beraspal. Sehingga sangat memungkinkan untuk menggunakan transportasi beroda dua maupun beroda empat.

Namun masih ada kekurangan pada akses menuju Pantai Dream Island. Walaupun infrastruktur jalannya mendukung dan bisa dilalui oleh transportasi roda dua maupun roda empat tempat ini masih belum memiliki penunjuk jalan. Hal ini tentunya menyulitkan wisatawan yang akan datang ke tempat ini terutama bagi wisatawan yang baru pertama kali ingin menuju ke pantai ini. Dan juga bagi lahan parkir yang terletak didepan pintu masuk, jalanan tersebut masih belum beraspal dan berbatu sehingga perlu dilakukan pembenahan agar lebih memudahkan wisatawan dalam memarkirkan kendaraannya.

\section{Amenity ( Fasilitas )}

Berdasarkan observasi yang di lakukan oleh peneliti amenitas yang ada di Pantai Dream Island kurang memadai. Seperti toilet umum mereka hanya menyedikan dua toilet yang berada di restoran. Hal kurang memungkinkan bagi wisatawan yang ingin ke toilet saat kondisi pantai sedang ramai pengunjung. Kurangnya toilet bisa membuat antrian panjang untuk menggunakan toilet ini membuat wisatawan yang datang kesana akan kurang nyaman.

Mereka juga belom memiliki toko souvenir dimana setiap wisatawan yang datang kesana bisa membeli jajanan khas atau cindera mata yang unik dari Pantai ini. Tidak adannya klinik sebagai tempat pertolongan pertama bagi wisatawan ketika terjadi kecelakaan juga masih belum ada, sehinnga hal ini juga harus diperhatikan oleh pihak pengelola.

Untuk ruang ganti yang tersedia di tempat ini sudah cukup banyak terdapat sepuluh ruang ganti yang terdiri dari lima kamar ganti untuk pria dan lima kamar ganti untuk perempuan. Di dalam ruang ganti tersebut juga sudah terdapat loker untuk menyimpan barang-barang wisatawan yang datang kesana. Disini sudah tersedia tempat bermain anak dan juga tempat penyewaan sepeda bagi wisatawan yang ingin berkeliling menggunakan sepeda. Untuk itu kedepannya diharapkan pengelola dapat membangun fasilitas yang lebih lengkap agar semakin membuat wisatawan lebih nyaman ketika berkunjung.

\section{Ancilliary ( Pelayanan Tambahan )}

Berdasarkan observasi dan wawancara peneliti dengan pengelola Pantai Dream Island yang mengelola Pantai ini adalah pihak swasta atau milik perorangan sehingga segala bentuk pengelolaanya diatur oleh manajemen tertinggi yang ada di perusahaan tersebut. Pantai Dream Island ini juga dinaungi oleh LPD Desa Pakraman Intaran. Sehingga setiap urusan administrasi yang ada harus dilaporkan ke LPD Desa Pakraman Intaran. Hal ini dikarenakan Pantai Dream Island berada di lahan milik Desa Pakraman Intaran. Oleh karena itu dalam pengelolaanya Pantai Dream Island melibatkan warga desa setempat untuk menjadi tenaga kerjanya. 


\subsection{STRATEGI BAURAN PEMASARAN}

Strategi Bauran Pemasaran yang akan dibahas adalah seluruh upaya yang dilakukan untuk perencanaan produk, harga, tempat, dan promosi. Hal-hal tersebut merupakan faktorfaktor yang mendukung dalam kegiatan pemasaran pariwisata.

\section{Product}

Produk wisata yang ada di Pantai Dream Island adalah snorkeling, sepeda air, cano, dan memberi makan hiu. Untuk menikmati produk wisata tersebut wisatawan bisa melakukannya langsung pada saat wisatawan kesana. Kegiatan lain yang bisa dinikmati oleh wisatwan adalah spa di tepi pantai ini akan menjadi pengalaman yang menarik bagi wisatawan yang menikmatinya. Lalu produk wisata yang disediakan adalah berkeliling pantai menggunakan unta atau kuda. Wisatawan akan menikmati sensasi seperti menaiki unta di padang gurun.

Lalu kegiatan entertainment di malam hari seperti : dinner di tepi pantai, menikmati penampilan fire dance, drum stick, dan tarian Bali. Kita juga dapat menikmati permainan music dari Dj yang tampil disana. Uniknya lagi para karyawan yang bekerja disana akan membuat tema setiap minggu, mereka juga menggunakan kostum yang sesuai tema yang sedang berlangsung. Sejauh ini tema yang paling sering dipakai adalah bajak laut dan zaman purba. Ini merupakan nilai tambah bagi pihak pengelola karena telah membuat suatu kegiatan yang mudah diingat wisatawan.

Berdasarkan observasi peneliti packaging dari produk wisata yang ada di Pantai Dream Island sudah bagus. Hanya saja pemasarannya belum maksimal sehingga banyak wisatawan yang tidak tahu mengenai keindahan Pantai ini.

\section{Price}

Harga yang dimaksud disini adalah nilai yang ditetapkan oleh pengelola Pantai Dream Island untuk tiket masuk maupun setiap produk yang disediakan.

Penentuan harga tiket masuk dan setiap kegiatan wisata disini didasari dengan pertimbangan-pertimbangan tertentu seperti modal awal, keuntungan yang didapat, pajak, jasa pelayanan, biaya pelayanan dan sebagainya.
Penentuan harga juga harus sesuai dengan target pasar yang dituju agar dapat dijangkau oleh mereka. Dalam hal ini target pasar mereka adalah wisatawan Tiongkok dan Lokal. Harga yang diberikan harus seusai dengan jasa pelayanan yang akan diterima oleh wistawan.

Untuk menikmati setiap kegiatan wisata yang ada di Pantai Dream Island harga yang perlu dikeluarkan oleh wisatawan sangat terjangkau. Hal ini berlaku bagi wisatawan asing maupun lokal karena tidak ada perbedaan harga. Untuk setiap harga yang sudah ditentukan disana pihak pengelola sudah memperhitungkan segala aspek yang menyangkut dalam proses operasianal dan biaya perawatan yang ada di Pantai Dream Island.

Berdasarkan observasi peneliti di lapangan adapun harga yang ditawarkan untuk masuk ke Pantai Dream Island dan paket wisata yang ditawarkan adalah :

- Dewasa : Rp. 20.000/pax

- Anak-anak : Rp. $15.000 /$ pax

- Dinner Package : Rp. 100.000/pax

- Foto Prewedding : Rp.1.500.000

- Spa $\quad$ :Rp. 75.000 - Rp. 200.000

- Unta dan Kuda : Rp. 50.000/25 menit Memberi makan hiu : Rp. 50.000

\section{Place}

Tempat diasosiasikan sebagai saluran distribusi yang ditujukan untuk mencapai target konsumen. Sistem distribusi ini mencakup lokasi, transportasi, pergudangan, dan sebagainya. Saluran distribusi pemasaran Pantai Dream Island melakukannya dengan dua cara yaitu pemasaran langsung dan tidak langsung. Untuk pemasaran langsung wisatawan datang langsung ke tempat tanpa melalui perantara. Sedangkan untuk pemasaran tidak langsung pihak pengelola bekerjasama dengan travel agent untuk memasarkan destinasi wisatanya.

\section{Promotion}

Berdasarkan wawancara dengan pihak pengelola kegitan promosi di Pantai Dream Island sudah berjalan yaitu melalui promosi di travel agent, dan social media. Namun untuk saat ini belum maksimal dikarenakan masih banyak 
kekurangan dalam hal media promosi seperti brosur, iklan, dan baliho. Lalu juga permasalahan ijin menjadi salah satu masalah yang belum mendapatkan solusinya, sehingga pihak pengelola masih belum berani melakukan pemasaran yang luas.

Untuk saat ini media promosi seperti social media menjadi salah satu yang akan dikembangkan sehingga kedepannya bisa mendatangkan lebih banyak lagi wisatawan yang berkunjung ke Pantai Dream Island. Harapan dari pengelola adalah target kunjungan wistawan tahun depan dapat meningkat sehingga eksistensi Pantai Dream Island semakin banyak dikenal masyarakat.

\section{People}

Berdasarkan wawancara dengan pihak pengelola karyawan yang berada di Pantai Dream Island ada sekitar 50 orang yang terdiri dari: securitiy, ticketing, office boy dan office girl, waitress, entertainer, koki, terapis Spa, dan manajemen Kantor.

Setiap karyawan yang ingin bekerja di Pantai Dream Island akan diberikan pelatihan terlebih dahulu agar dapat mengetahui jobdesk masingmasing. Selain pelatihan skill pengelola Pantai Dream Island juga memberikan dasar-dasar dalam beretika seperti cara dalam melayani tamu dan menghadapi complain. Pihak pengelola juga mengadakan gathering tujuannya agar memperkuat kerjasama dan komitmen dari setiap karyawan.

\section{Process}

Process, mutu layanan jasa sangat bergantung pada proses penyampaian jasa kepada konsumen. Mengingat bahwa penggerak perusahaan jasa adalah karyawan itu sendiri, maka untuk menjamin mutu layanan (quality assurance), seluruh operasional perusahaan harus dijalankan sesuai dengan sistem dan prosedur yang terstandarisasi oleh karyawan yang berkompetensi, berkomitmen, dan loyal terhadap perusahaan tempatnya bekerja.

Berdasarkan observasi pengelolaan Pantai Dream Island sudah berjalan sesuai dengan standar operasional. Namun mereka belum memiliki standar operasional secara tertulis. Jadi mereka hanya mengikuti standar opersional yang berlaku seperti di perusahaan lain.

\section{Physical Evidence}

Building merupakan bagian dari bukti fisik, karakteristik yang menjadi persyaratan yang bernilai tambah bagi konsumen dalam perusahaan jasa yang memiliki karakter. Perhatian terhadap interior, perlengkapan bangunan, termasuk lightning system, dan tata ruang yang lapang menjadi perhatian penting dan dapat mempengaruhi mood pengunjung. Berdasarkan Observasi Bangunan yang ada di Pantai Dream Island berwawasan lingkungan hal ini dikarenakan material bangunan yang digunakan masih alami seperti penggunaan kayu dan ilalang pada bangunan dan atap restoran dan lumbung spa. Mereka juga memanfaatkan pepohonan yang ada disana untuk digunakan sebagai tempat ayunan. Hal ini menjadi sebuah daya tarik bagi wisatawan karena disana wisatawan dapat beristirahat sambil menikmati panorama laut yang indah.

\section{PENUTUP}

Pantai Dream Island memiliki potensi pariwisata yang sangat bagus. Bila dilihat kondisi eksistingnya berdasarkan konsep 4A Pantai Dream Island sudah memadai karena pantai ini mmemiliki atraksi alam yang indah, begitu juga ataraksi buatan yang sangat menonjol. Untuk akses menuju pantai ini sangat mudah karena infrastruktur jalan yang memadai sehingga memudahkan kendaraan roda 4 maupun roda 2 untuk masuk kesana. Untuk fasilitas yang disediakan oleh pihak pengelola belom memadai karena masih ada beberapa fasilitas seperti toilet yang kurang banyak, toko souvenir, dan klinik kesehatan untuk pertolongan pertama apabila terjadi kecelekaan.Untuk kelembagaan mereka hanya terdiri dari pihak swasta dan lembaga desa saja. Strategi pemasaran yang diterapkan di Pantai Dream Island belum optimal dikarenakan sarana promosi yang kurang. Pihak pengelola masih berupaya untuk mengembangkan target pasarnya dan juga menjalin kerjasama antar media promosi. 


\section{DAFTAR PUSTAKA,}

Anom, I. P., Suryasih, I. A., Nugroho, S., \& Mahagangga, I. G. A. O. (2017). Turismemorfosis: Tahapan selama seratus tahun perkembangan dan prediksi pariwisata Bali. Jurnal Kajian Bali (Journal of Bali Studies), 7(2), 59-80.

Arikunto, (1993), Prosedur Penelitian, Suatu Pendekatan Praktek, Edisi Kesembilan, Rineka Cipta, Jakarta.

Basu, Swastha. (1996). Azas-Azas Marketing. Edisi 3. Liberty: Yogyakarta.

Bungin, Burhan. (2007). Penelitian Kualitatif: Komunikasi, Ekonomi, Kebijakan Publik dan Ilmu Sosial lainnya.Jakarta: Putra Grafika

Cooper, C., Fletcher, J., Gilbert, D., \& Wanhill, S. (1996).Tourism Principle \& Practice. London: Longman Group Limited.

Creswell, J. W. (2012) Educational research: Planning, conducting, and evaluating Quantitative and qualitative research

David, Fred, R. (2011). Strategic Management Manajemen Strategi Konsep, Edisi 12, Salemba Empat, Jakarta.

Elsa, E. (2017). Peran Pariwisata dalam Meningkatkan Pertumbuhan Ekonomi Masyarakat. Jurnal Spasial, 3(1).

Fandy Tjiptono. (2006). Manajemen Jasa. Edisi Pertama. Yogyakarta : Andi

Joehastanti, Jenny. "Strategi Pemasaran Wisata Alam Untuk Meningkatkan Kunjungan Wisatawan Di Kawasan Wisata Kabupaten Kediri." Jurnal Ilmu Manajemen, REVITALISASI 1.2 (2012).

Karta, N. L. P. A., \& Suarthana, I. K. P. (2014). Strategi komunikasi pemasaran ekowisata pada destinasi wisata Dolphin Hunting Lovina. Matrik: Jurnal Manajemen, Strategi Bisnis dan Kewirausahaan.

Kotler, Philip \& Amstrong, (1997). Dasar-Dasar Pemasaran, jilid 1 dan 2, Jakarta.

Kotler, Philip \& Armstrong, Gary. (2012). Principles of Marketing. New Jersey: Prentice Hall.

Kusmayadi Sugiarto, E. (2000). Metodologi Dalam Bidang Kepariwisataan.

Moleong, P. (2005). Dr. Lexy J. Metodologi Penelitian Kualitatif.

Moleong, L. J. (2012). Metodologi Penelitian Kualitatif Edisi Revisi Cet. Ketigapuluh.

Ratu, Cristina, \& I. Made Adikampana. "Strategi Pemasaran Desa Wisata Blimbingsari Kabupaten Jembrana." Jurnal Destinasi Pariwisata (2016): 60-67.

Sugiyono. (2005). Memahami Penelitian Kualitatif. Bandung: ALFABET.

Sugiyono. (2014). Metode Penelitian Pendidikan Pendekatan Kuantitatif,Kualitatif Dan R\&D.Bandung: Alfabeta.

Setyadin. (2005). "Metode Penelitian Kualitatif: Teori Dan Praktik". Jakarta: Bumi Akasra.

Yulianda, F. ( 2007). Ekowisata Bahari Sebagai Alternatif Pemanfaatan Sumberdaya Pesisir Berbasis Konservasi (Disampaikan pada 